in vivo $36: 603-609(2022)$

doi:10.21873/invivo.12743

\title{
Gadodiamide Induced Autophagy and Apoptosis in Human Keratinocytes
}

\author{
YUH-FENG TSAI ${ }^{1,2}$, JAI-SING YANG $^{3}$, YU-JEN CHIU ${ }^{4,5,6}$, \\ CHIA-WEN TSAI ${ }^{7,8}$, DA-TIAN BAU ${ }^{7,8,9}$ and WEN-SHIN CHANG ${ }^{7,8}$ \\ ${ }^{1}$ Department of Diagnostic Radiology, Shin-Kong Wu Ho-Su Memorial Hospital, Taipei, Taiwan, R.O.C.; \\ ${ }^{2}$ School of Medicine, Fu-Jen Catholic University, New Taipei, Taiwan, R.O.C.; \\ ${ }^{3}$ Department of Medical Research, China Medical University Hospital, \\ China Medical University, Taichung, Taiwan, R.O.C.; \\ ${ }^{4}$ Division of Plastic and Reconstructive Surgery, Department of Surgery, \\ Taipei Veterans General Hospital, Taipei, Taiwan, R.O.C.; \\ ${ }^{5}$ Department of Surgery, School of Medicine, National Yang Ming Chiao Tung University, Taipei, Taiwan, R.O.C.; \\ ${ }^{6}$ Institute of Clinical Medicine, National Yang Ming Chiao Tung University, Taipei, Taiwan, R.O.C.; \\ ${ }^{7}$ Graduate Institute of Biomedical Sciences, China Medical University, Taichung, Taiwan, R.O.C.; \\ ${ }^{8}$ Terry Fox Cancer Research Laboratory, Department of Medical Research, \\ China Medical University Hospital, Taichung, Taiwan, R.O.C.; \\ ${ }^{9}$ Department of Bioinformatics and Medical Engineering, Asia University, Taichung, Taiwan, R.O.C.
}

\begin{abstract}
Background/Aim: Gadolinium has been reported to cause liver lobular necrosis and nephrogenic systemic fibrosis. However, its toxicity to the skin remains unknown. This study aimed to investigate the effect of a high dose of gadolinium-based contrast agent gadodiamide on the human keratinocyte HaCaT cell line. Materials and Methods: Cell viability was assessed using MTT assay, and autophagy was assessed using acridine orange and LysoTracker Red staining. Western blotting was performed to verify the changes in Bcl2 and Bax levels. Results: The viability of HaCaT cells was significantly suppressed after gadodiamide treatment. Interestingly, gadodiamide caused autophagic vacuoles, whereas the autophagy inhibitors 3-methyladenine and chloroquine significantly alleviated autophagic cell death. Simultaneously, gadodiamide induced apoptosis, which was reduced by caspase inhibitors. Gadodiamide also inhibited Bcl-2 expression and promoted Bax expression. Conclusion: Gadodiamide induced both autophagy and
\end{abstract}

This article is freely accessible online.

Correspondence to: Da-Tian Bau and Wen-Shin Chang, Terry Fox Cancer Research Laboratory, Department of Medical Research, China Medical University Hospital, 2 Yuh-Der Road, Taichung, 404 Taiwan, R.O.C. Tel: +886 422053366 (Ext. 5805), e-mail: artbau2@gmail.com

Key Words: Apoptosis, autophagy, gadodiamide, $\mathrm{HaCaT}$ cells. apoptosis in HaCaT cells. Physicians should carefully assess the gadodiamide dosage used clinically.

Magnetic resonance imaging (MRI) is a contemporary technology that produces three-dimensional images of the anatomical human body and helps in the detection and diagnosis of diseases. The density of contrast agents produces a strong contrast effect; however, patients with severe renal failure may be at risk of a serious illness called nephrogenic systemic fibrosis (NSF) that may be linked to the use of certain gadolinium-based contrast agents (GBCAs) such as gadodiamide $(1,2)$. GBCAs agents can be applied to the human body, providing anatomical imaging of the head, spinal cord, and vascular artery for doctors to determine the condition of the entire body (3). However, its toxicity to normal skin cells is critical, but has never been investigated.

NSF is a serious, late adverse reaction to gadodiamide (4, 5). Thus, the Taiwan Food and Drug Administration suggests the use of the lowest effective dose to prevent possible adverse effects on any part of the human body $(6,7)$. Longterm ionized gadolinium accumulation may cause fibrosis in various tissues of the human body, including the skin. Early alterations and symptoms of NSF may include pain, itching, swelling, and erythema, which usually start in the legs. Late lesions may include thickening of the skin and subcutaneous tissues, visceral fibrosis, and finally severe symptoms like limb contracture, cachexia, and death $(8,9)$. However, the detailed mechanisms remain largely unknown. The main purpose of the current study was to explore whether high 
concentrations of gadodiamide (Omniscan ${ }^{\circledR}$ ) cause irreversible damage in a human keratinocyte cell model and to determine the mechanisms involved.

\section{Materials and Methods}

Cell culture conditions. Human keratinocyte HaCaT cells were cultured in $10 \%$ foetal bovine serum, containing MEM, supplemented with $100 \mathrm{U} / \mathrm{ml}$ penicillin, $0.1 \mathrm{mg} / \mathrm{ml}$ streptomycin, and $2 \mathrm{mM} \mathrm{L}$-glutamine, and maintained in an incubator at $37^{\circ} \mathrm{C}, 5 \%$ $\mathrm{CO}_{2}$, and $95 \%$ relative humidity.

Reagents. Gadodiamide was acquired by Dr. Yuh-Feng Tsai from the Shin-Kong Wu Ho-Su Memorial Hospital. Other necessary chemicals, such as phosphate buffered saline (PBS), dimethyl sulfoxide (DMSO), 3-(4,5-dimethylthiazol-2-yl)-2,5diphenyltetrazoliumbromide (MTT), acridine orange (AO), 3methyladenine (3-MA), and chloroquine (CQ), were purchased from Sigma Chemical Co. (St. Louis, MO, USA).

Cell viability assessment. Cell viability was assayed using the MTT assay (10). HaCaT cells were seeded in a 96-well culture dish for $24 \mathrm{~h}$ of incubation to allow cell attachment. After successful attachment, various concentrations $(0.65,1.3,2.6,5.2,13$, and 26 $\mathrm{mM}$ ) of gadodiamide were added followed by incubation for $24 \mathrm{~h}$. The surviving cells were subjected to MTT assay for $4 \mathrm{~h}$, and the final absorbance at $570 \mathrm{~nm}$ was measured using a spectrophotometer. The experiment was repeated at least thrice. The half-maximal inhibitory concentration $\left(\mathrm{IC}_{50}\right)$ of gadodiamide against $\mathrm{HaCaT}$ cells has been previously reported $(11,12)$.

AO staining of autophagic vacuoles. HaCaT cells were treated with gadodiamide, washed with PBS, and stained with $1 \mathrm{ml}$ of fresh medium containing $1 \mu \mathrm{g} / \mathrm{ml} \mathrm{AO}$ for $20 \mathrm{~min}$ at $37^{\circ} \mathrm{C}$. Acidic vesicular organelles and autophagy vacuoles were observed under an inverted fluorescence microscope and analysed using a NucleoCounter NC-3000 (ChemoMetec A/S) (13). The cytoplasm and nucleus of AO-stained cells fluoresced bright green, whereas the acidic autophagic vacuoles fluoresced bright red. Red fluorescence intensity was used to quantify gadodiamide-induced autophagy. To verify specific gadodiamide-induced autophagy, the cells were pre-treated with $10 \mathrm{mM} 3$-methyladenine (3-MA) or 10 $\mathrm{nM}$ chloroquine (CQ) for $4 \mathrm{~h}$ and then incubated in the absence of gadodiamide for $24 \mathrm{~h}$ (13-15).

LysoTracker Red staining for autophagy. Gadodiamide-treated $\mathrm{HaCaT}$ cells were washed with PBS and $1 \mathrm{ml}$ of fresh medium containing LysoTracker Red $(1 \mu \mathrm{g} / \mathrm{ml})$ for $20 \mathrm{~min}$. The appearance of bright red small cells, a typical autophagy cell, was observed under an inverted fluorescence microscope (14).

DAPI was used for apoptotic nuclear staining. Briefly, HaCaT cells were seeded at a density of $2 \times 10^{5}$ in a six-well culture plate for 24 h. After attachment, HaCaT cells were treated with gadodiamide and incubated for $24 \mathrm{~h}$, followed by an ethanol $70 \%$ (v/v) fixing reaction for $15 \mathrm{~min}$. HaCaT cells were washed with PBS and stained with DAPI $(125 \mathrm{ng} / \mathrm{ml})$ for $30 \mathrm{~min}$ in the dark. The apoptotic nuclei of $\mathrm{HaCaT}$ cells were observed for specific morphological alterations, such as volume reduction and chromatin condensation, directly under a fluorescence microscope (16).

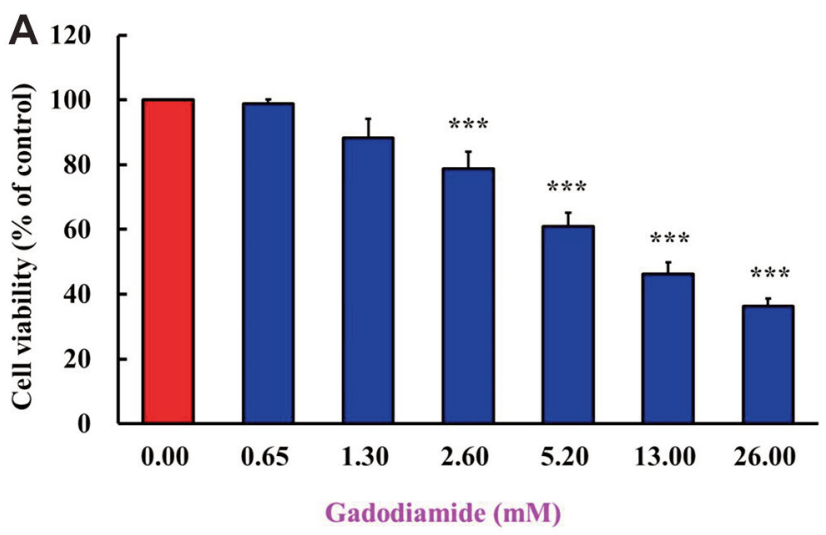

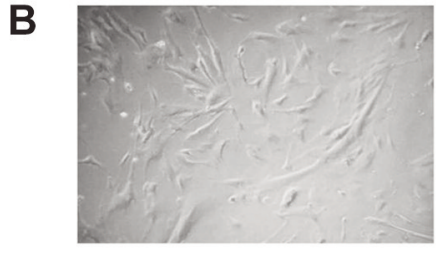

Control

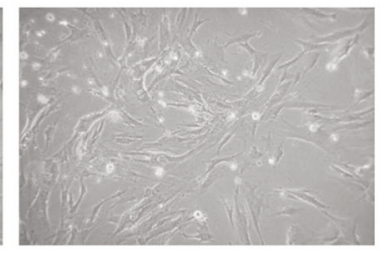

Gadodiamide (13 mM)
Figure 1. Gadodiamide suppressed HaCaT cell viability. (A) HaCaT cells $\left(5 \times 10^{4}\right.$ cells/well $)$ were incubated for $24 \mathrm{~h}$ with $0,0.65,1.3,2.6$, $5.2,13$, or $26 \mathrm{mM}$ of gadodiamide. HaCaT cell viability was assessed using the MTT assay. The results are normalized using the vehicletreated control as $100 \%(n=3 ; * * *<<0.05)$. (B) Cell morphology of HaCaT cells was observed after treatment with $13 \mathrm{mM}$ gadodiamide for 24 h. Left: vehicle-treated control; right: $13 \mathrm{mM}$ gadodiamidetreated cells.

Spectrophotometric assay for caspase 3 activity. The fluorochromelabeled inhibitor of caspases assay (FLICA) method was applied using the FAM-FLICA ${ }^{\circledR}$ Caspases 3 Assay Kit (ImmunoChemistry Technologies, LLC; Bloomington, MN, USA, cat. no. 93), and achieving the typical spectrophotometric assay at $405 \mathrm{~nm}$ using the NucleoCounter NC-3000 (13).

Western blotting for the detection of translational expression. The cells were harvested and lysed in lysis buffer. Equal amounts of protein samples $(100 \mu \mathrm{g}$ per lane) were separated using $10 \%$ sodium dodecyl sulphate-polyacrylamide gel electrophoresis. The bands were transferred onto a polyvinylidene difluoride membrane, blocked in $5 \%$ non-fat milk, and then incubated with primary antibodies overnight at $4{ }^{\circ} \mathrm{C}$. Bcl2 and $\mathrm{Bax}$ were detected using specific horseradish peroxidase-conjugated secondary antibodies. Finally, the proteins were visualized using an enhanced chemiluminescence detection kit (Amersham Pharmacia Biotech, Lawrenceville, NJ, USA). The ImageJ software was used to analyse the expression of $\mathrm{Bcl} 2$ and $\mathrm{Bax}$, which were both normalized to $\beta$ actin $(17,18)$.

Statistical analyses. Each experiment was conducted at least thrice. The data are presented as the mean \pm standard deviation. Statistical differences were evaluated using one-way analysis of variance. Differences were considered statistically significant at $p<0.05$. 


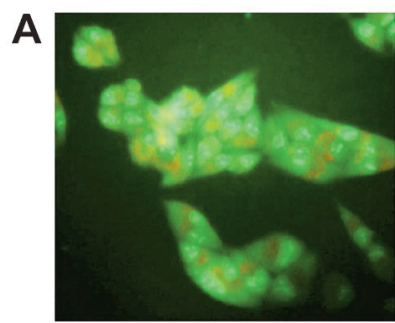

Control

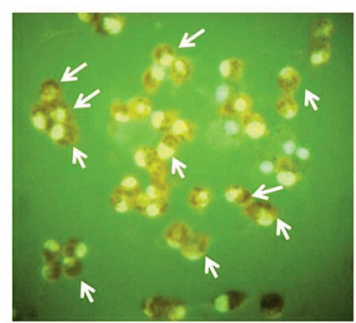

Gadodiamide (13 mM)

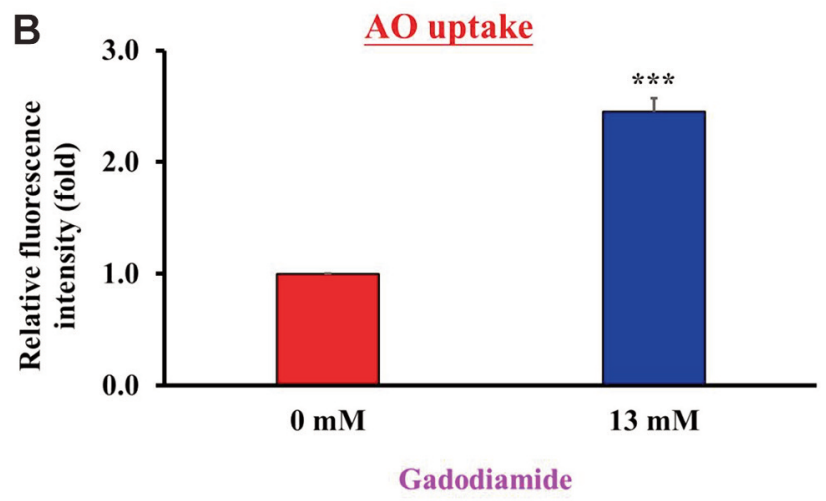

Figure 2. Gadodiamide induced autophagy in HaCaT cells. (A) Fluorescence images of acridine orange (AO)-stained HaCaT cells after treatment with or without $13 \mathrm{mM}$ gadodiamide; left: vehicle-treated control; right: $13 \mathrm{mM}$ gadodiamide-treated cells. (B) Quantitative data for HaCaT cells treated with or without $13 \mathrm{mM}$ gadodiamide treatment. *Statistically significant difference from vehicle-treated control cells.

A
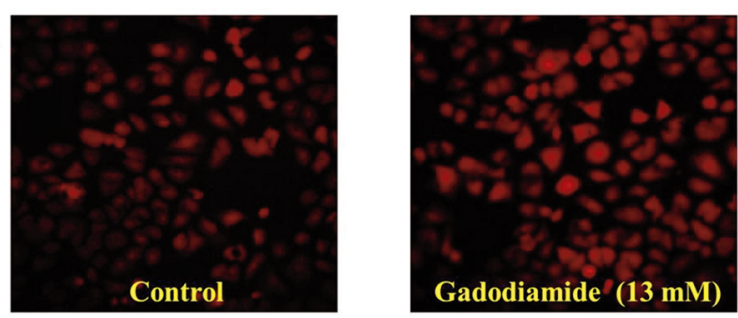

B

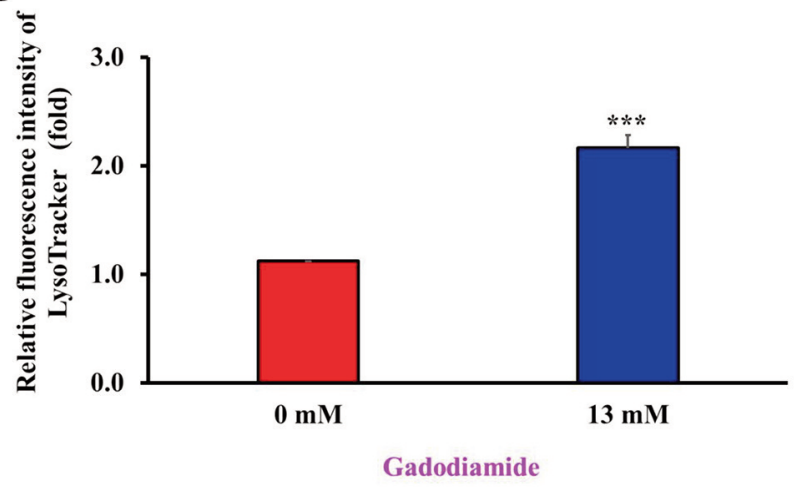

Figure 3. Gadodiamide induced lysosomal membrane permeability. (A) Fluorescence images of LysoTracker Red-stained HaCaT cells after treatment with or without $13 \mathrm{mM}$ gadodiamide; left: vehicle-treated control; right: $13 \mathrm{mM}$ gadodiamide-treated cells. (B) Quantitative data for HaCaT cells treated with or without $13 \mathrm{mM}$ gadodiamide treatment. ***Statistically significant difference from vehicle-treated control cells.
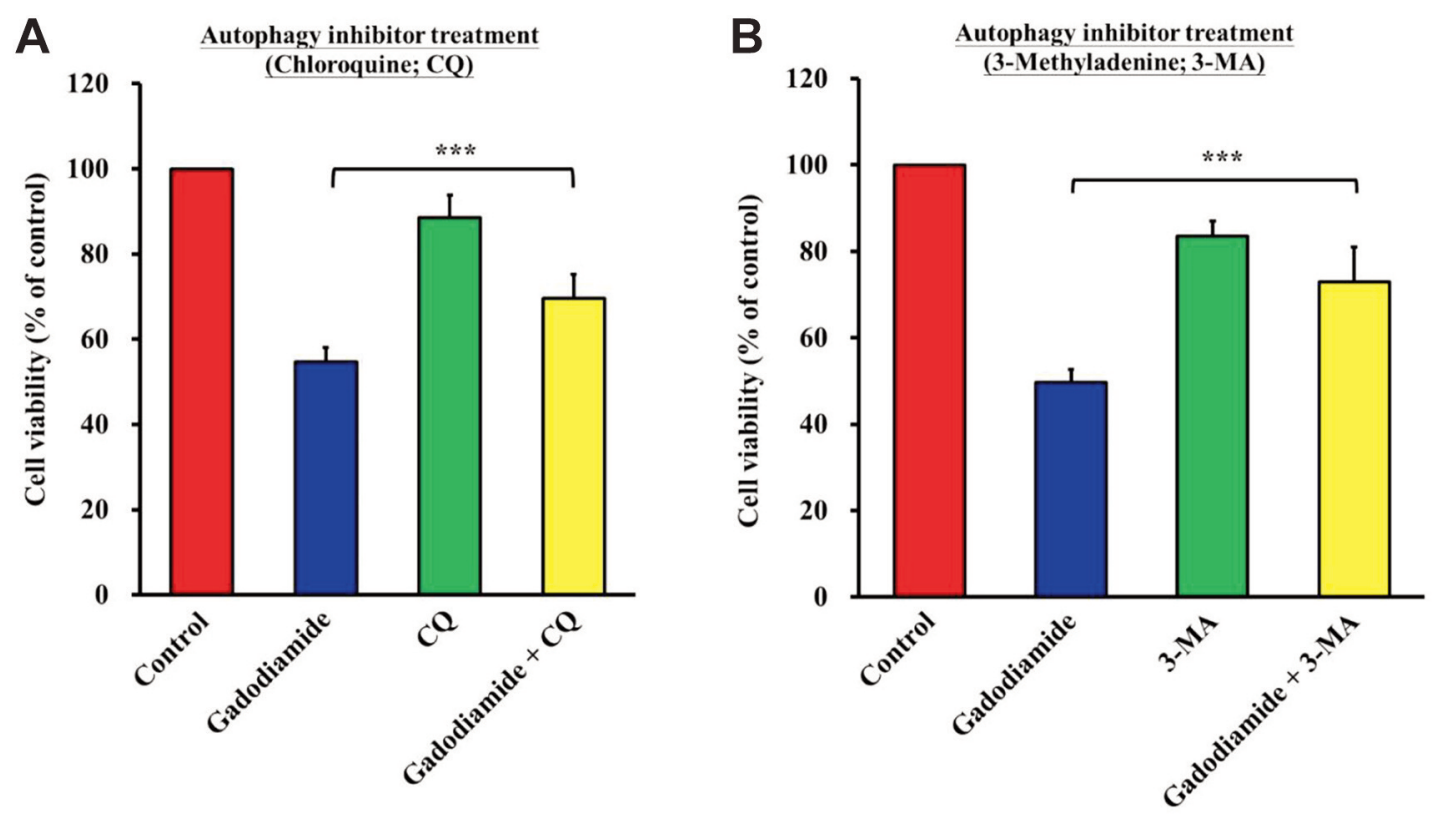

Figure 4. Autophagy inhibitors can restore HaCaT cell viability. (A) HaCaT cells were vehicle-treated, treated with 13 mM gadodiamide alone, chloroquine (CQ) alone, or gadodiamide plus CQ. (B) HaCaT cells were vehicle-treated, treated with 13 mM gadodiamide alone, 3-methyladenine (3-MA) alone, or gadodiamide plus 3-MA. ***Statistically significant difference from vehicle-treated control cells. 

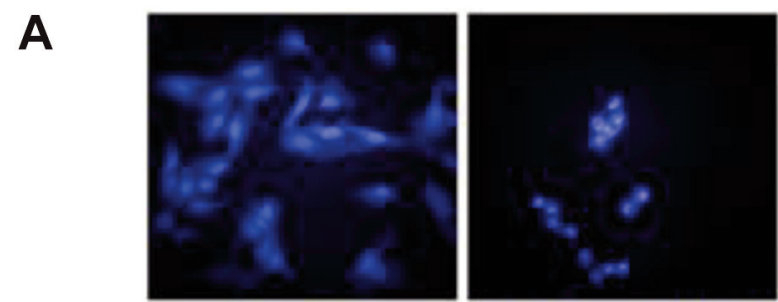

Control

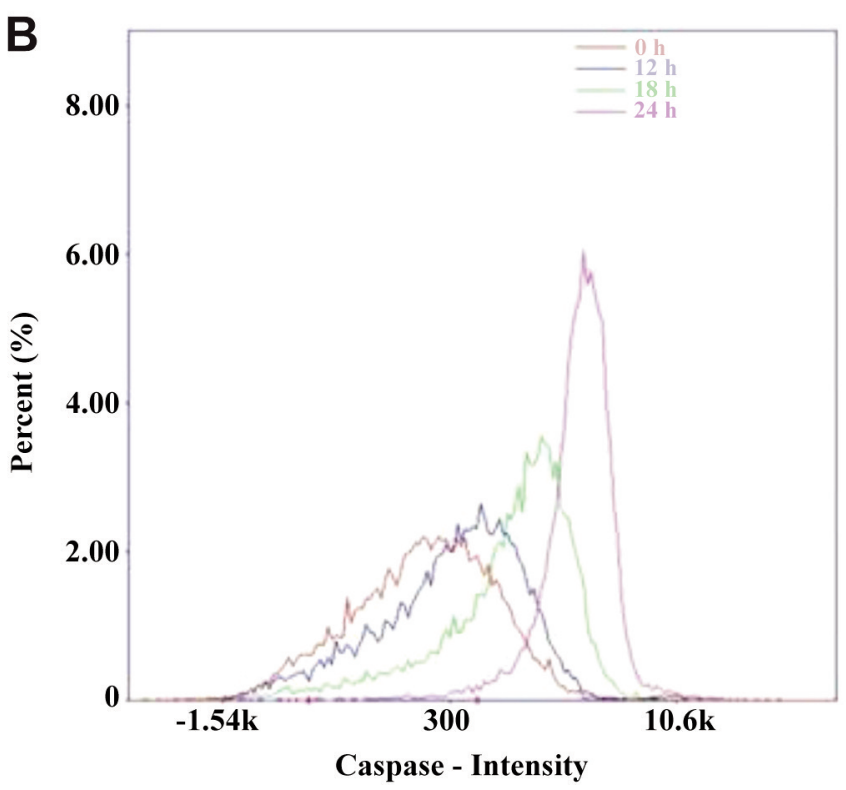

Figure 5. Gadodiamide induced HaCaT cell apoptosis. (A) Fluorescence images of chromatin condensation in HaCaT cells after treatment with or without $13 \mathrm{mM}$ gadodiamide; left: vehicle-treated control; right: $13 \mathrm{mM}$ gadodiamide-treated cells. (B) Time-dependent increase of the caspase intensity by $13 \mathrm{mM}$ gadodiamide treatment at 0, 12, 18, and $24 \mathrm{~h}$. (C) Quantitative data for HaCaT cells treated with $13 \mathrm{mM}$ gadodiamide at 0,12 , 18 , and $24 h$.**Statistically significant difference from vehicle-treated control cells.

\section{Results}

Gadodiamide significantly suppressed HaCaT cell viability. $\mathrm{HaCaT}$ cells were treated with gadodiamide $(0,0.65,1.3,2.6$, $5.2,13$, and $26 \mathrm{mM}$ ) for $24 \mathrm{~h}$ and cell viability was assessed using the MTT assay. Gadodiamide suppressed $\mathrm{HaCaT}$ cell viability in a concentration-dependent manner from 2.6 to 26 $\mathrm{mM}$ (Figure 1A). After $24 \mathrm{~h}$ of treatment with $13 \mathrm{mM}$ gadodiamide, cell morphology was altered and showed cell shrinkage and a round shape (Figure 1B). These data showed that $\mathrm{HaCaT}$ cells undergo programmed cell death.

Gadodiamide induced autophagy in HaCaT cells. Both apoptosis and autophagy are important for regulating cell fate. Apoptosis and autophagy share similar regulatory systems, such as $\mathrm{p} 53, \mathrm{Bcl}$ family proteins, FADD, and Atg proteins $(19,20)$. We hypothesized that gadodiamide induces autophagy in $\mathrm{HaCaT}$ cells. To this end, $\mathrm{HaCaT}$ cells were treated with or without $13 \mathrm{mM}$ gadodiamide, and $\mathrm{AO}$ staining was conducted to assess the appearance of autophagic vacuoles. Gadodiamide treatment resulted in the formation of autophagic vacuoles (Figure 2A). Quantitative data showed that gadodiamide significantly increased the fluorescence intensity (Figure 2B). Our findings indicate that gadodiamide also induced an autophagic response in addition to inducing apoptosis.

To verify these new findings, we applied another methodology called LysoTracker Red staining, which is a fluorescent stain for acidic lysosomes. HaCaT cells were treated with or without $13 \mathrm{mM}$ gadodiamide and subjected to LysoTracker Red staining to observe the changes in lysosomes. Indeed, autophagy-related proteins significantly increased in the gadodiamide-treated group (Figure 3A). The quantitative results showed that gadodiamide significantly increased the fluorescence intensity (Figure 3B). We have provided evidence for the novel finding that gadodiamide induced autophagy in $\mathrm{HaCaT}$ cells using both $\mathrm{AO}$ and LysoTracker Red staining. 
A

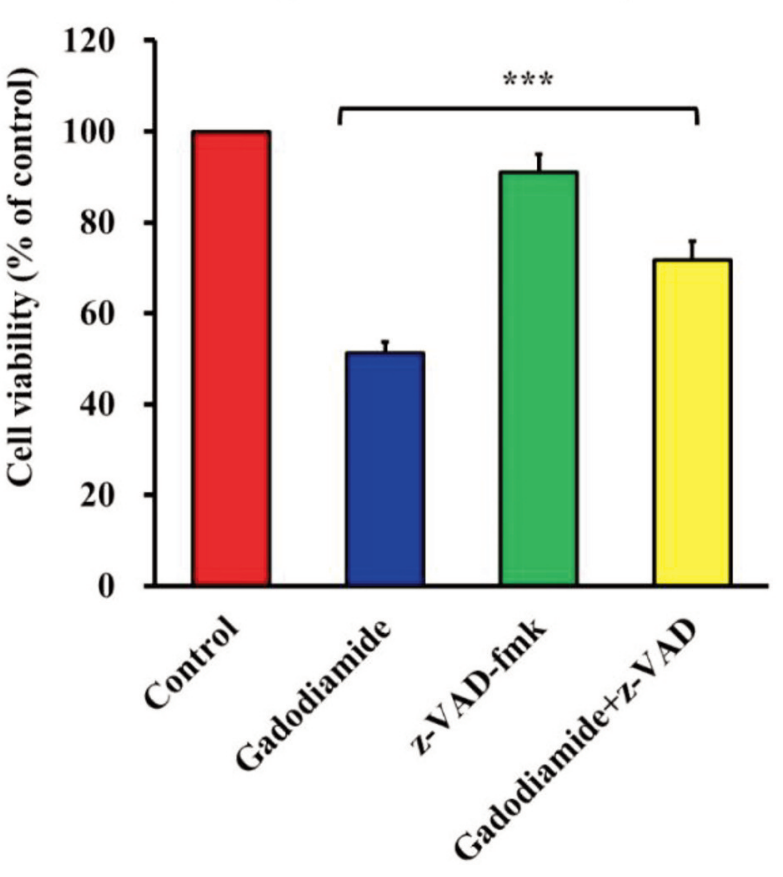

Caspase-3 inhibitor treatment (z-DEVD-fmk)

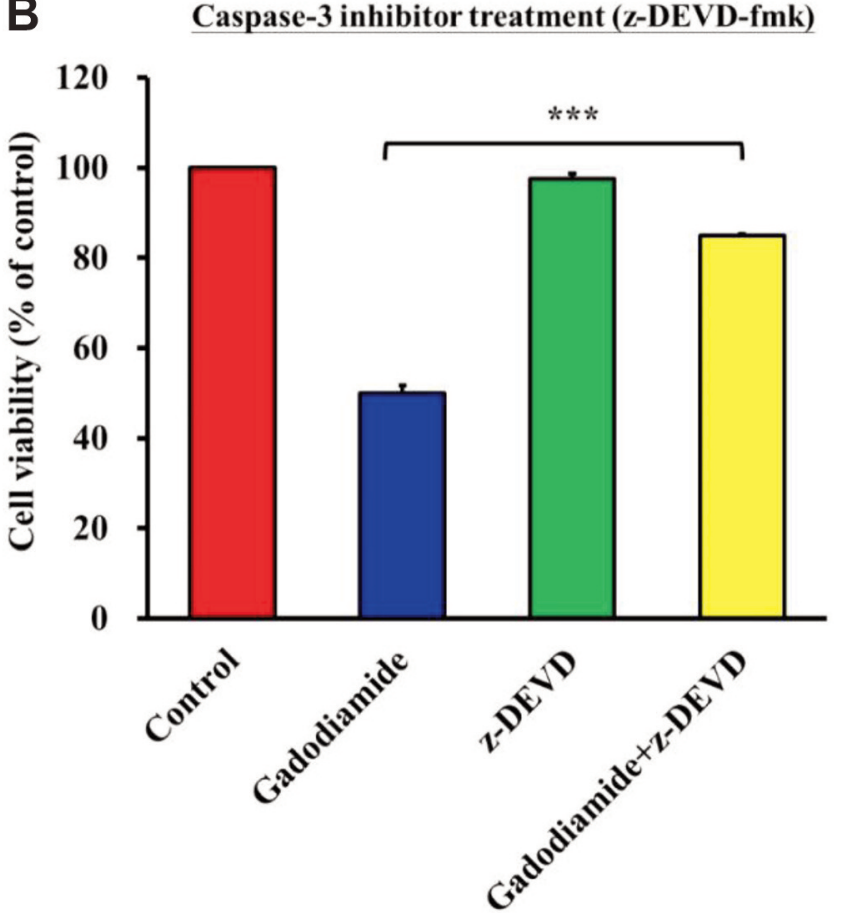

Figure 6. Apoptotic inhibitor can restore HaCaT cell viability. (A) HaCaT cells were vehicle-treated, treated with 13 mM gadodiamide alone, pancaspase inhibitor (z-VAD) alone, or gadodiamide plus z-VAD. (B) HaCaT cells were vehicle-treated, treated with 13 mM gadodiamide alone, caspase3 inhibitor $(z-D E V D)$ alone, or gadodiamide plus z-DEVD. ***Statistically significant different from vehicle-treated control cells.

Gadodiamide-induced cell death was decreased by cotreatment with autophagy inhibitors. To demonstrate that gadodiamide-induced autophagy is specific to gadodiamidemediated cytotoxicity, $\mathrm{HaCaT}$ cells were co-treated with the autophagy inhibitors 3-MA or CQ and gadodiamide for $24 \mathrm{~h}$. The results showed that the gadodiamide-induced suppression of cell viability was successfully rescued by co-treatment with CQ (Figure 4A) and 3-MA (Figure 4B). CQ or 3-MA alone had no effect on the viability of HaCaT cells. In summary, gadodiamide induced autophagy in HaCaT cells.

Gadodiamide induced HaCaT cell apoptosis. Autophagy may not be the only pathway involved in gadodiamideinduced cell death in HaCaT cells. Next, we checked for chromatin condensation, a morphological hallmark of apoptotic cell death. HaCaT cells were treated with or without $13 \mathrm{mM}$ gadodiamide followed by DAPI staining. The number of brightly fluoresced and fragmented nuclei was higher in gadodiamide-treated $\mathrm{HaCaT}$ cells than in control HaCaT cells (Figure 5A). Supporting evidence for gadodiamide-induced apoptosis in $\mathrm{HaCaT}$ cells was provided by increased caspase intensity after treatment with $13 \mathrm{mM}$ gadodiamide in a time-dependent manner (Figure 5B) and increased caspase 3 activity after the same treatment (Figure 5C).

\section{Gadodiamide (13 mM)}

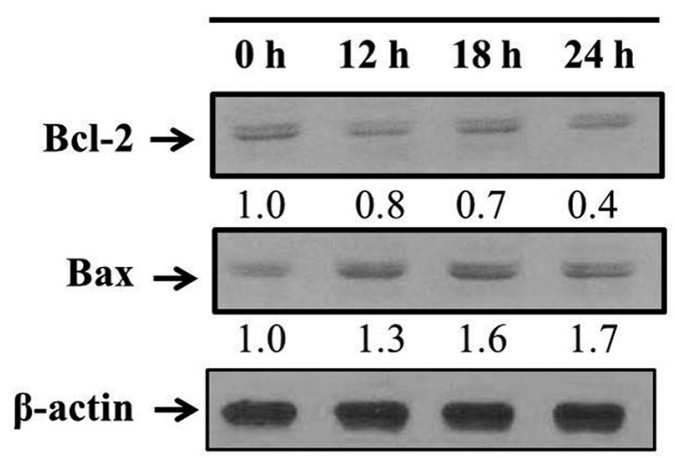

Figure 7. Gadodiamide affected the expression of mitochondrial proteins in HaCaT cells. Gadodiamide decreased the expression levels of Bcl-2 and increased the expression levels of Bax at 0, 12, 18, and 24 $h$ after treatment.

Gadodiamide-induced cell death was decreased by cotreatment with apoptotic inhibitors. After demonstrating that gadodiamide also induced apoptosis in $\mathrm{HaCaT}$ cells, we used the pan-caspase inhibitor (z-VAD) and caspase-3 inhibitor (z-DEVD) to evaluate their effects on gadodiamide-induced cell death in HaCaT cells. HaCaT cells were treated with or 
without $13 \mathrm{mM}$ gadodiamide in the absence or presence of z-VAD (Figure 6A) or z-DEVD (Figure 6B), followed by a cell viability assay. The results showed that gadodiamide induced apoptosis, which could be alleviated by both the pan-caspase inhibitors z-VAD and z-DEVD in HaCaT cells.

Finally, western blotting was conducted to detect the translational levels of $\mathrm{Bcl}-2$ and Bax proteins. The results showed a significant decrease in Bcl-2 expression and an increase in Bax expression after treating $\mathrm{HaCaT}$ cells with $13 \mathrm{mM}$ gadodiamide (Figure 7), providing evidence for the involvement of mitochondrial dysfunction after gadodiamide treatment in $\mathrm{HaCaT}$ cells.

\section{Discussion}

GBCAs have the advantage of enhancing the image contrast between healthy and abnormal tissues in MRI scans in greater detail (21). Although GBCAs have been approved by the FDA for the use in patients, gadolinium is believed to be toxic to humans. Gadolinium has been reported to cause central lobular necrosis in the liver and NSF in the kidney (22). In our previous studies, we provided evidence that gadodiamide can induce cell death in normal brain glial SVG P12 cells $(10,23)$. High levels of gadodiamide (with the same dosage used in the current study) may induce significant cytotoxicity in the brain, although gadodiamide has been proven by the FDA to be applied to the central nervous system $(6,24)$. The current challenges with existing GBCAs necessitate the development of multimodal contrast agents with better biocompatibility and lower or no toxicity.

To date, NSF seems to be the most severe symptom of gadodiamide retention in body tissues. Gadolinium metal ions are replaced by a contrast agent compound (transmetalation) and free gadolinium ions are deposited in various tissues, such as the skin, leading to fibrosis $(23,25)$. However, the detailed mechanisms underlying skin toxicity have not yet been elucidated. Thus, in this study, we wanted to unveil the underlying mechanisms.

To address this, we tested the toxicity of gadodiamide in normal human keratinocyte $\mathrm{HaCaT}$ cells. First, we found that gadodiamide treatment for $24 \mathrm{~h}$ suppressed $\mathrm{HaCaT}$ cell viability at doses greater than $2.6 \mathrm{mM}$ (Figure 1). One highlight of this study is the finding that a high dose of gadodiamide (13 mM) was capable of inducing autophagy in cells (Figure 2 and Figure 3), which was further confirmed using autophagy inhibitors (Figure 4). Although we did not observe alterations in the levels of autophagy-specific proteins, AO staining showed that autophagic vacuoles were indeed formed in the gadodiamide-treated $\mathrm{HaCaT}$ cells (Figure 2). In addition, loss of mitochondrial integrity was observed with LysoTracker Red staining (Figure 3). Further investigations are needed to determine how gadodiamide induces autophagy and to develop useful drugs to prevent autophagy.
Another highlight is that a high dose of gadodiamide can induce apoptosis in HaCaT cells. Currently, we can only provide evidence that gadodiamide can cause mitochondrial dysfunction, leading to apoptosis, and $\mathrm{Bcl} 2$ and $\mathrm{Bax}$ are involved in this phenomenon (Figure 7). However, the detailed mechanism remains unclear. It was hypothesized that the cytochrome $\mathrm{c}$ that is released from the mitochondria may bind to Apaf-1, which activates caspase cascade signalling $(23,26)$. In the current study, we only provide evidence that cleaved-caspase-3 (Figure 5B), together with its activity (Figure 5C), is involved in gadodiamide-induced cytotoxicity. The use of pan-caspase inhibitors may inform us more about the involvement of other caspases, such as caspase- 8 and caspase- 9 .

In summary, this pilot study showed that $13 \mathrm{mM}$ gadodiamide induced both autophagy and apoptosis in human skin cells. This study determined whether gadodiamide has toxicological effects and provides safety guidance for its application in modern MRI technology. Physicians should pay attention to the precise and personalized dose of gadodiamide to yield better clinical images and simultaneously prevent any toxicity.

\section{Conflicts of Interest}

All Authors declare no conflicts of interest in relation to this study.

\section{Authors' Contributions}

YFT, JSY, and WSC conceived and designed the experiments; YJC and CWT performed the experiments; YFT, DTB, CWT, and JSY analysed the data; and JSY, DTB, and WSC wrote and revised the manuscript. All Authors have approved the manuscript and agreed to be accountable for all aspects of the research to ensure that the accuracy or integrity of any part of the work is appropriately investigated and resolved.

\section{Acknowledgements}

The present study was supported by a project supervised by Tsai in Shin-Kong Wu Ho-Su Memorial Hospital (grant no. 2019SKHDR035) and partially by the project supervised by Bau at China Medical University Hospital (grant no. DMR-111-144). The Authors would also like to thank the Office of Research and Development, China Medical University (Taiwan, ROC) for providing Medical Research Core Facilities to perform the experiments and data analysis.

\section{References}

1 Chang AL, Yu HJ, von Borstel D, Nozaki T, Horiuchi S, Terada $\mathrm{Y}$ and Yoshioka H: Advanced imaging techniques of the wrist. AJR Am J Roentgenol 209(3): 497-510, 2017. PMID: 28829171. DOI: $10.2214 / A J R .17 .18012$

2 Czeyda-Pommersheim F, Martin DR, Costello JR and Kalb B: Contrast agents for MR imaging. Magn Reson Imaging Clin N 
Am 25(4): 705-711, 2017. PMID: 28964460. DOI: 10.1016/ j.mric.2017.06.011

3 Martí-Bonmatí L and Martí-Bonmatí E: Retention of gadolinium compounds used in magnetic resonance imaging: a critical review and the recommendations of regulatory agencies. Radiologia 59(6): 469-477, 2017. PMID: 29110904. DOI: 10.1016/j.rx.2017.09.007

4 Thomsen HS, Marckmann P and Logager VB: Nephrogenic systemic fibrosis (NSF): a late adverse reaction to some of the gadolinium based contrast agents. Cancer Imaging 7: 130-137, 2007. PMID: 17905680. DOI: 10.1102/1470-7330.2007.0019

5 Morcos SK: Nephrogenic systemic fibrosis following the administration of extracellular gadolinium based contrast agents: is the stability of the contrast agent molecule an important factor in the pathogenesis of this condition? Br J Radiol 80(950): 7376, 2007. PMID: 17392401. DOI: $10.1259 / \mathrm{bjr} / 17111243$

6 Strickler SE and Clark KR: Gadolinium deposition: a study review. Radiol Technol 92(3): 249-258, 2021. PMID: 33472877.

7 Costa AF, van der Pol CB, Maralani PJ, McInnes MDF, Shewchuk JR, Verma R, Hurrell C and Schieda N: Gadolinium deposition in the brain: a systematic review of existing guidelines and policy statement issued by the Canadian Association of Radiologists. Can Assoc Radiol J 69(4): 373-382, 2018. PMID: 30249408. DOI: 10.1016/j.carj.2018.04.002

8 Beam AS, Moore KG, Gillis SN, Ford KF, Gray T, Steinwinder $\mathrm{AH}$ and Graham A: GBCAs and risk for nephrogenic systemic fibrosis: a literature review. Radiol Technol 88(6): 583-589, 2017. PMID: 28900045.

9 Malikova H and Holesta M: Gadolinium contrast agents - are they really safe? J Vasc Access 18(Suppl. 2): 1-7, 2017. PMID: 28362042. DOI: $10.5301 /$ jva.5000713

10 Tsai YF, Chen YF, Hsiao CY, Huang CW, Lu CC, Tsai SC and Yang JS: Caspase dependent apoptotic death by gadolinium chloride $(\mathrm{GdCl} 3)$ via reactive oxygen species production and MAPK signaling in rat C6 glioma cells. Oncol Rep 41(2): 13241332, 2019. PMID: 30535448. DOI: 10.3892/or.2018.6913

11 Lin CC, Chen KB, Tsai CH, Tsai FJ, Huang CY, Tang CH, Yang JS, Hsu YM, Peng SF and Chung JG: Casticin inhibits human prostate cancer DU 145 cell migration and invasion via Ras/Akt/NF-kB signaling pathways. J Food Biochem 43(7): e12902, 2019. PMID: 31353708. DOI: 10.1111/jfbc.12902

12 Ha HA, Yang JS, Tsai FJ, Li CW, Cheng YD, Li J, Hour MJ and Chiu YJ: Establishment of a novel temozolomide resistant subline of glioblastoma multiforme cells and comparative transcriptome analysis with parental cells. Anticancer Res 41(5): 2333-2347, 2021. PMID: 33952458. DOI: 10.21873/anticanres.15008

13 Ha HA, Chiang JH, Tsai FJ, Bau DT, Juan YN, Lo YH, Hour MJ and Yang JS: Novel quinazolinone MJ 33 induces AKT/mTOR mediated autophagy associated apoptosis in 5FU resistant colorectal cancer cells. Oncol Rep 45(2): 680-692, 2021. PMID: 33416156. DOI: 10.3892/or.2020.7882

14 Chang CH, Lee CY, Lu CC, Tsai FJ, Hsu YM, Tsao JW, Juan YN, Chiu HY, Yang JS and Wang CC: Resveratrol-induced autophagy and apoptosis in cisplatin-resistant human oral cancer CAR cells: A key role of AMPK and Akt/mTOR signaling. Int J Oncol 50(3): 873-882, 2017. PMID: 28197628. DOI: 10.3892/ ijo.2017.3866

15 Yang JS, Lu CC, Kuo SC, Hsu YM, Tsai SC, Chen SY, Chen YT, Lin YJ, Huang YC, Chen CJ, Lin WD, Liao WL, Lin WY, Liu YH, Sheu JC and Tsai FJ: Autophagy and its link to type II diabetes mellitus. Biomedicine (Taipei) 7(2): 8, 2017. PMID: 28612706. DOI: 10.1051/bmden/2017070201

16 Chang PY, Tsai FJ, Bau DT, Hsu YM, Yang JS, Tu MG and Chiang SL: Potential effects of allyl isothiocyanate on inhibiting cellular proliferation and inducing apoptotic pathway in human cisplatin-resistant oral cancer cells. J Formos Med Assoc 120(1 Pt 2): 515-523, 2021. PMID: 32624316. DOI: 10.1016/j.jfma. 2020.06 .025

17 Wu KM, Hsu YM, Ying MC, Tsai FJ, Tsai CH, Chung JG, Yang JS, Tang CH, Cheng LY, Su PH, Viswanadha VP, Kuo WW and Huang CY: High-density lipoprotein ameliorates palmitic acidinduced lipotoxicity and oxidative dysfunction in $\mathrm{H} 9 \mathrm{c} 2$ cardiomyoblast cells via ROS suppression. Nutr Metab (Lond) 16: 36, 2019. PMID: 31149020. DOI: 10.1186/s12986-019-0356-5

18 Hsu SW, Hsu PC, Chang WS, Yu CC, Wang YC, Yang JS, Tsai FJ, Chen KY, Tsai CW and Bau DT: Protective effects of valproic acid on 6-hydroxydopamine-induced neuroinjury. Environ Toxicol 35(8): 840-848, 2020. PMID: 32167238. DOI: 10.1002/tox.22920

19 Thorburn A: Apoptosis and autophagy: regulatory connections between two supposedly different processes. Apoptosis 13(1): 19, 2008. PMID: 17990121. DOI: 10.1007/s10495-007-0154-9

20 Tsai YF, Yang JS, Tsai FJ, Cheng YD, Chiu YJ and Tsai SC: High concentration of iopromide induces apoptosis and autophagy in human embryonic kidney cells via activating a ROS-dependent cellular stress pathway. In Vivo 35(6): 32213232, 2021. PMID: 34697153. DOI: 10.21873/invivo.12617

21 Michaely HJ, Aschauer M, Deutschmann H, Bongartz G, Gutberlet M, Woitek R, Ertl-Wagner B, Kucharczyk W, Hammersting1 R, De Cobelli F, Rosenberg M, Balzer T and Endrikat J: Gadobutrol in renally impaired patients: results of the GRIP study. Invest Radiol 52(1): 55-60, 2017. PMID: 27529464. DOI: $10.1097 /$ RLI.0000000000000307

22 Behzadi AH and Prince MR: Immediate reaction to gadolinium based contrast agent with fatal outcome. Radiol Case Rep 13(5): 1091-1092, 2018. PMID: 30228851. DOI: 10.1016/j.radcr. 2018.06.009

23 Tsai YF, Yang JS, Tsai FJ, Lu CC, Chiu YJ and Tsai SC: In vitro toxicological assessment of gadodiamide in normal brain SVG P12 cells. In Vivo 35(5): 2621-2630, 2021. PMID: 34410949. DOI: 10.21873 /invivo.12544

24 Chehabeddine L, Al Saleh T, Baalbaki M, Saleh E, Khoury SJ and Hannoun S: Cumulative administrations of gadoliniumbased contrast agents: risks of accumulation and toxicity of linear vs. macrocyclic agents. Crit Rev Toxicol 49(3): 262-279, 2019. PMID: 30942117. DOI: 10.1080/10408444.2019.1592109

25 Lange S, Mędrzycka-Dąbrowska W, Zorena K, Dąbrowski S, Ślęzak D, Malecka-Dubiela A and Rutkowski P: Nephrogenic systemic fibrosis as a complication after gadolinium-containing contrast agents: a rapid review. Int J Environ Res Public Health 18(6): 3000, 2021. PMID: 33804005. DOI: 10.3390/ijerph18063000

26 Noori AR, Tashakor A, Nikkhah M, Eriksson LA, Hosseinkhani $\mathrm{S}$ and Fearnhead HO: Loss of WD2 subdomain of Apaf-1 forms an apoptosome structure which blocks activation of caspase-3 and caspase-9. Biochimie 180: 23-29, 2021. PMID: 33132160. DOI: 10.1016/j.biochi.2020.10.013

Received January 21, 2022

Revised February 3, 2022

Accepted February 4, 2022 